\title{
PENSAMENTO E SOCIEDADE: CONTRIBUIÇÕES AO DEBATE SOBRE A EXPERIÊNCIA DO ENEM
}

\author{
Cintya Regina RiBEIRo*
}

\begin{abstract}
RESUMO: O artigo problematiza os modos de enfrentamento das questões sobre o pensamento em educação, a partir da experiência brasileira do Exame Nacional de Ensino Médio (Enem). Considerando a relevância política desse exame, sobretudo em relação às atuais condições de acesso ao ensino superior, tal prática efetiva-se simultaneamente como avaliativa e curricular. A partir de uma perspectiva teórica que afirma as implicações entre linguagem e poder, a análise fundamenta-se no pensamento de Friedrich Nietzsche e Michel Foucault, particularmente quanto à questão da produção de conhecimento e seus atuais efeitos frente à configuração do pensamento na sociedade. Apontamos que as discussões dos autores contribuem para o atual debate sobre a qualidade da educação básica e superior, pois incitam a problematização dos aspectos de recognição e performance presentes nessa prática educacional.
\end{abstract}

Palavras-chave: Enem. Pensamento. Recognição. Performance. Currículo.

\section{THOUGHT AND SOCIETY: CONTRIBUTIONS TO THE DEBATE ON THE EXPERIENCE OF ENEM}

ABSTRACT: The article discusses the ways of confronting issues about thinking in education, based on the Brazilian experience of the National Examination of Secondary Education (Enem). Considering the political importance of this examination, especially in relation to the current conditions of access to higher education, this practice is effective as both evaluative and curricular. From a theoretical perspective that asserts the implications between language and power, the analysis is based on the thought of Friedrich Nietzsche and Michel Foucault, particularly in relation to the question of knowledge production and its effects against the current configuration of thought in society. We point out that discussions of these authors contribute to the current debate about the quality of basic and higher education, because it enables questioning aspects of recognition and performance in this educational practice.

Key words: Enem. Thought. Recognition. Performance. Curriculum.

* $\quad$ Faculdade de Educação da Universidade de São Paulo (USP). São Paulo (SP) - Brasil.

Contato com a autora: <cintyaribeiro@usp.br> 


\title{
Pensée et SOCiÉté: \\ CONTRIBUTIONS AU DÉBAT SUR L'EXPÉRIENCE DE L'ENEM
}

\begin{abstract}
RÉSUMÉ: L'article discute les manières de faire face à des sujets sur la pensée dans l'enseignement, à partir de l'expérience brésilienne de l'Examen National de l'Enseignement Secondaire (Enem). Considérant la pertinence politique de cet examen, surtout par rapport aux conditions actuelles d'accès à l'enseignement supérieur. Telle pratique est considérée à la fois évaluative et scolaire. En prenant comme point de départ une perspective théorique qui affirme les implications entre le langage et le pouvoir, l'analyse s'appuie sur la pensée de Friedrich Nietzsche et Michel Foucault, particulièrement quant au sujet de la production de connaissance et de ses effets actuels en face de la configuration de la pensée en société. Nous estimons que les discussions des auteurs contribuent au débat actuel sur la qualité de l'enseignement de base et y compris l'enseignement supérieur, car ils provoquent la problématisation des aspects de recognition et de performance présents dans cette pratique d'enseignement.
\end{abstract}

Mots-Clés: Enem. Pensée. Recognition. Performance. Cursus universitaire.

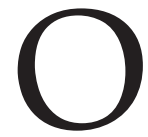

presente estudo tem como objetivo problematizar os modos de enfrentamento das questões sobre o pensamento em educação, tomando como foco as práticas do Exame Nacional de Ensino Médio (Enem) realizadas no Brasil. Orientada numa perspectiva teórica que assume as imbricações entre linguagem e poder, a análise fundamenta-se no pensamento de Friedrich Nietzsche e Michel Foucault, particularmente no que tange à questão da produção de conhecimento na modernidade e seus efeitos na contemporaneidade. Defendemos que as inflexões dos pensadores nessa direção configuram potentes recursos analíticos para fomentar o debate de questões atuais relativas ao currículo, ao conhecimento e ao pensamento em educação.

No intuito de evocarmos as tensões preliminares que perpassam o problema do conhecimento e do pensamento, propomos uma breve incursão literária, explorando a densidade do pequeno conto do escritor uruguaio Eduardo Galeano (2009, p. 15), intitulado A função da arte/1:

Diego não conhecia o mar. O pai, Santiago Kovakloff, levou-o para que descobrisse o mar. Viajaram para o Sul. Ele, o mar, estava do outro lado das dunas altas, esperando. Quando o menino e o pai enfim alcançaram aquelas alturas de areia, depois de muito caminhar, o mar estava na frente de seus olhos. E foi tanta a imensidão do mar, e tanto seu fulgor, que o menino ficou mudo de beleza. E quando finalmente conseguiu falar, tremendo, gaguejando, pediu ao pai: - Me ajuda a olhar!

Por meio da metáfora do olhar, a breve narrativa sugere a experiência do conhecimento como efeito de uma mobilização estética derivada do contato entre gerações. Dos múltiplos efeitos literários, interessa-nos colocar em evidência quatro 
aspectos: 1) de largada, o título afirma uma condição de funcionalidade da arte; 2) a indicação da série numérica denota multiplicidade, ou seja, não haveria uma única função atribuída à experiência estética; 3) o efeito de sofisticação do olhar advindo dessa experiência não se faria espontaneamente, mas se constituiria a partir de uma relação mestre-discípulo, aqui representada pelo vínculo intergeracional; 4) a funcionalidade dessa experiência estética seria de qualificação imponderável, não passível de mensuração.

O paralelismo da discussão desse conto com as questões relativas ao campo educacional não é mera retórica estilística. Nessa aproximação, buscamos evocar esse carácter performativo do conhecimento - no caso, o aprendizado da sofisticação do olhar como um objeto de conhecimento no campo da arte -, tendo em vista estabelecer alguns pontos de convergência com os debates educacionais atuais.

Asseguradas as respectivas singularidades dos universos da arte e educação, a experiência de sofisticação do olhar também parece ser conclamada como metáfora oportuna para a função educativa na atualidade. Os dilemas da educação escolar se movem entre o inapreensível do mar e o imensurável do conhecer.

A despeito da ausência de quaisquer referências explícitas ao campo educativo, o conto insinua que uma possível função da arte seria forjar uma ocasião de partilha para o aprendizado do olhar - uma espécie de educação do olhar. A concepção de educação aqui presumida supõe uma experiência de ensino e aprendizagem que, embora lastreada pela necessidade de repasse da herança cultural por meio da relação entre pai e filho, consubstancializa-se, antes, na experiência de partilha de um ato, de certo saber fazer, enfim.

O jogo literário então proposto produz a instigante transgressão de sentido em relação à ideia de funcionalidade, sequestrando-a de seu universo utilitarista clássico, constituído pela linguagem da racionalidade técnica, e arremessando-a noutra direção - tão intangível quanto mais potente. Aqui, a "funcionalidade" da arte remeteria, paradoxalmente, ao imponderável de seu uso, ao intangível de sua dimensão aplicativa e, ao mesmo tempo, à qualidade intensiva dessa experiência estética vivenciada tão somente como uma impulsão para um deslocamento radical.

Essa reconfiguração da experiência formativa oferece-nos uma senha para a exploração de questões candentes em relação às práticas educacionais formais na atualidade.

Ao solicitar ao pai a ajuda para olhar, o menino de Galeano desloca um acontecimento casual da vida cotidiana para um status de experiência de aprendizagem, de vivência educacional. Se prosseguirmos a digressão fabulatória agora num cenário eminentemente pedagógico, a virtualidade do jogo metafórico permite-nos redimensionar filosoficamente o pleito do garoto: - Me ensina a olhar; ou, mais precisamente: 
- Me ensina a pensar. Trata-se aqui da reivindicação do aprendizado do inefável, do informe, daquilo que seria refratário às malhas da substantivação e que remeteria à experiência singular de infinitude do verbo, portanto. Por aproximação, o aprendizado do olhar constituiria a densificação da experiência estética na mesma intensidade que o aprendizado do pensar expressaria a condição de excelência da experiência educativa.

Essa valoração da condição performativa do objeto do conhecimento tem se manifestado em múltiplas práticas da cultura ocidental contemporânea. No âmbito desse trabalho, circunscrevemos a formação básica de nível médio como um dos lugares privilegiados no qual ocorre essa prevalência discursiva. Aqui, o objeto do conhecimento também se substancializa como ação: um aprendizado da sofisticação de atos cognitivos. Do ponto de vista das políticas públicas, esse caráter performático do conhecer traduz-se em termos de ensino e aprendizagem do pensar.

Entretanto, se, de um lado, se aposta na dimensão intensiva do ato de pensar como um diferencial educacional, por outro lado, se demanda que, na contramão do espírito de Galeano, os atos de pensamento sejam atestados e avaliados em sua materialidade manifesta, ou seja, em termos de resultados, de efeitos apreensíveis. Seriam esses produtos de pensamento, definidos e legitimados a priori, que expressariam o aprendizado do próprio ato de pensar, tornando-o passível de qualificação, mensuração e traçados projetivos.

A matriz de referência contida nos documentos pedagógicos nacionais para o ensino médio (BRASIL, 2009a), composta por eixos cognitivos, competências e habilidades, bem como seu desdobramento na forma da prática avaliativa do Enem parece-nos expressões paradigmáticas desse modo de abordagem do pensamento.

As implicações dessa perspectiva, na qual o conhecimento educativo materializa-se como ato de pensamento e não tão somente como domínio cumulativo da herança cultural clássica, tornam inevitável o redimensionamento do problema curricular.

Tomaz Tadeu da Silva (2001), pesquisador brasileiro tido como referência na área de teoria curricular, aponta que, no âmbito da educação formal, foi no horizonte do início do século XX que o problema do conhecimento formulou-se pedagogicamente como uma questão de currículo.

Embora nos alinhemos a essa perspectiva analítica que estabelece uma relação constitutiva entre as questões de currículo e o problema do conhecimento, apontamos a necessidade de desdobrar e precisar essa articulação. Sustentamos a hipótese de que as discussões sobre questões curriculares devem ultrapassar o foco generalista do problema do conhecimento e ensaiar problematizações no campo do pensamento, ou, mais especificamente, nos modos como as práticas de pensamento são engendradas e legitimadas na materialidade curricular. 
Tal postura analítica fundamenta-se no legado intelectual de Nietzsche (1998, 2001, 2008) e Foucault $(1995,1998$ a, 1998b, 1999a, 1999b, 1999c, 2001, 2005, 2008a, $2008 b$ ), uma vez que, para tais pensadores, ao focalizarmos as questões do conhecimento, acionamos uma problematização da linguagem, condição que nos lança inevitavelmente a uma analítica do pensamento.

Ancorados em tais pressupostos, traçaremos uma configuração mais precisa do território educacional em questão.

\section{Alguns elementos do atual cenário curricular no Brasil}

De modo breve, resgatemos que o preceito educacional do aprender a aprender, princípio que perpassa o debate curricular nacional e internacional contemporâneo, encontra no Relatório Jacques Delors (2002) sua peça emblemática. O documento postula quatro pilares necessários à educação para o século XXI: o primeiro deles aprender a conhecer - e seus sucessores: aprender a fazer, a conviver e a ser.

Um de seus efeitos foi a elaboração de uma agenda para que diversos países reorientassem suas políticas públicas, redimensionando seus documentos curriculares e avaliativos. O Brasil não esteve alheio a tal empreita: a formulação da Lei de Diretrizes e Bases da Educação Nacional (LDB) e a construção de documentos especificamente curriculares, voltados aos diversos níveis da educação básica, são manifestações dessa tendência.

Articuladas a tais transformações, foram implementadas progressivamente as avaliações sistêmicas, de modo que o Estado pudesse aferir as convergências entre a proposição das políticas públicas educacionais e os efeitos concretos de ensino e aprendizagem no cotidiano das escolas.

Foi nesse horizonte que, em 1998, o Brasil institui o Exame Nacional de Ensino Médio (Enem). Formulado pelo Instituto Nacional de Estudos e Pesquisas Educacionais Anísio Teixeira (Inep), trata-se de uma prática avaliativa anual aplicável aos alunos concluintes e egressos deste nível de ensino, com o objetivo de mensurar seu desempenho cognitivo ao término da escolaridade básica.

Inicialmente, as variáveis a serem avaliadas foram sistematizadas numa matriz de cinco competências e 21 habilidades. Em 2009, o Inep apresentou um novo documento intitulado Matriz de referência para o Enem, qualificando cinco eixos cognitivos comuns a todas as áreas de conhecimento do ensino médio, além das respectivas competências e habilidades exigidas em cada uma das quatro áreas de conhecimento e suas tecnologias. O documento apresenta ainda um conjunto de "conteúdos" qualificado como "objetos de conhecimento associados às matrizes de referência", no qual são listados temas afins às respectivas áreas (BRASIL, 2009a; 2009b). 
No histórico desse modelo, definem-se:

Competências são as modalidades estruturais da inteligência, ou melhor, ações e operações que utilizamos para estabelecer relações com e entre objetos, situações, fenômenos e pessoas que desejamos conhecer. As habilidades decorrem das competências adquiridas e referem-se ao plano imediato do "saber fazer". (BRASIL, 2002)

Nessa proposta examinatória presume-se uma orientação curricular voltada ao trabalho com as operações cognitivas do sujeito, tendo em vista explorar suas competências de inteligência e habilitá-lo a lidar com as situações-problema da vida cotidiana. Isso implica investir pedagogicamente no desenvolvimento de capacidades intelectivas voltadas ao saber-fazer uso do conhecimento, seja aquele aprendido na escola ou na vida em geral.

Na formação desse ser social contemporâneo, busca-se desenvolver a capacidade cognitiva de resolução de problemas frente a uma ordem social mais ampla, marcada pela complexidade das mudanças. Assim, o documento explicita que "o sucesso do processo educativo é alcançado, segundo a visão construtivista da aprendizagem escolar, quando leva o aluno a 'aprender a pensar'"' (BRASIL, 2002).

Tais princípios indicam que pensar é saber-fazer uso do conhecimento em contextos adequados. A ênfase na expressão "aprender a pensar" afirma a necessidade de aprender a usar esse saber - situação que se qualificaria como o pensar. Embora o enunciado "aprender a pensar" não se explicite na atual Matriz de referência do Enem (BRASIL, 2009a), nela se reitera o conjunto de competências e habilidades originais, demonstrando a prevalência dos princípios que orientaram a formulação inicial dessa prática.

Interessa-nos destacar a ampliação e consolidação dessa estratégia avaliativa no Brasil, enfatizando sua atual relevância política como vetor de transição entre os níveis do ensino médio e superior, tanto no âmbito público como privado.

Dado o valor estratégico dos referidos critérios intelectivos no mapeamento da condição formativa de uma população - seu capital intelectual - o Enem tem se legitimado politicamente tanto como avaliação sistêmica relativa à qualidade do ensino médio no país, quanto como avaliação individual referente ao desempenho cognitivo dos alunos.

As notas do Enem podem ser computadas como recurso único, alternativo ou complementar nos processos de ingresso do aluno no ensino superior, seja na rede pública ou privada: por meio de mecanismos de seleção pela via do Sistema de Seleção Unificada (Sisu) do governo federal ou do processo de concessão de bolsas do Programa Universidade para Todos (Prouni) (BRASIL, 2010a, 2010b). 
O Enem se consolida porque, de um lado, torna-se baliza de uniformização da qualidade do ensino médio no país, conferindo um formato à educação básica; de outro lado, por afirmar-se como instrumento de validação do ingresso no ensino superior, atua como vetor de ampliação do acesso público a esse grau de formação.

O lugar estratégico que essa experiência vem conquistando em termos sociopolíticos torna imprescindível uma análise mais atenta em relação aos seus efeitos de médio e longo prazo, quando tomamos como alvo a questão do pensamento e da educação.

Evocando a companhia analítica nietzschiana e foucaultiana para dialogar com o campo educacional, cumpre-nos indagar: quais as singularidades e os efeitos possíveis dessa política de pensamento que, por meio de estratégias avaliativas e curriculares populacionais, se afirma como um regime de verdade para o campo educacional atual?

\section{O pensamento como objeto de governamentalização}

José Mario Pires Azanha (2006), a partir de uma filosofia analítica da linguagem, realiza uma crítica sobre o uso das expressões aprender a aprender e aprender a pensar no cenário da escola contemporânea, particularmente, no contexto brasileiro.

O autor esclarece que, em duas ocasiões referenciais (1982 e 1989), porém, com propósitos distintos, "a expressão 'aprender a aprender' foi interpretada como se significasse 'aprender a pensar'" (AZANHA, 2006, p. 19). Ele critica o caráter de abstracionismo das expressões, dada a ausência do contexto no qual são definidas, alertando que as definições devem remeter sempre ao contexto de seu uso. Essa situação conduziria ao uso retórico desses enunciados, produzindo uma "paralisação pedagógica" por parte de educadores e pesquisadores educacionais, pois não haveria clareza quanto ao significado desses enunciados em contextos pedagógicos cotidianos.

Azanha argumenta que o desdobramento da ideia de que aprender a aprender significaria aprender a pensar seria um dos esforços pedagógicos voltados à tentativa de conferir materialidade ao abstracionismo inicial. Para ele, o caráter autorreferencial da expressão aprender a aprender conduziria a uma situação confusa em relação ao modo de enfrentamento cotidiano das questões pedagógicas.

O traçado de uma matriz de referência composta por eixos cognitivos, competências e habilidades parece expressar esse esforço de materialização de qualidades intelectivas fundamentais. Evidencia-se, pois, que a questão contemporânea premente em termos educacionais formula-se como um problema de pensamento, ou seja, de ensino e aprendizagem de pensamento. 
Tomemos os eixos cognitivos dessa matriz: I. Dominar linguagens; II. Compreender fenômenos; III. Enfrentar situações-problema; IV. Construir argumentação; V. Elaborar propostas. Destaquemos alguns dos verbos utilizados na tábua de competências e habilidades: identificar, caracterizar, selecionar, reorganizar, relacionar, interpretar, analisar, situar, quantificar, calcular, descrever, confrontar, comparar, propor formas de intervenção, utilizar, ler, reconhecer, prever, traduzir, inferir, compreender, valorizar, contextualizar, ordenar, entre outros (BRASIL, 2009a).

A despeito da multiplicidade das ações intelectivas em foco, depreende-se uma concepção circunscrita, tanto do ato de pensar como do próprio pensamento. Pensar sugere, aqui, mero jogo de estabelecimento de relações entre categorias ou variáveis. Ainda que se reconheça que tal jogo promoveria o incremento da complexidade mental por meio da crescente sofisticação de conexões cognitivas, trata-se, no limite, tão somente de uma exercitação da reflexividade da razão. Estaríamos frente à produção em larga escala de um pensamento voltado à excelência técnica de ordenação e reprodução linguística desse mundo.

Daí a necessidade de tomarmos essa retórica de competência e habilidade no manuseio cognitivo de uma linguagem representacional do mundo como uma questão educacional mais ampla. Situamo-nos no dilema de nossas escolhas éticopolíticas acerca da validação de uma política de pensamento, com reverberação de efeitos formativos em longo prazo.

Defendemos que, nas discussões avaliativas e curriculares, para além de focalizarmos o processo de legitimação do conhecimento/herança cultural, faz-se necessário radicalizar o debate e evocar os jogos de pensamento constitutivos das práticas educacionais vigentes. Tocaríamos assim a própria nervura do problema: o esgarçamento da própria operação do pensar, efeito de conexões entre linguagem e poder.

$\mathrm{Na}$ atual formulação da matriz de referência do Enem, pensamento e objeto do conhecimento/pensamento aparecem como duas categorias epistemológicas bem demarcadas. Por esse viés, o ato de pensar se constituiria como mero jogo reflexivo, no qual são apreendidas e espelhadas as formas linguísticas prevalecentes de representação do mundo. Apontamos que esse modo de tomar o pensamento numa chave representacional e reflexiva tem naturalizado a experiência do conhecer como um trabalho tautológico pautado na prática da recognição.

Ainda que reconheçamos o caráter abstracionista dessa orientação pedagógica fundamentada no aprendizado do pensar, tal como sugerida por Azanha, sustentamos, numa perspectiva foucaultiana, que haveria uma implicação material, pragmática dessas produções discursivas na concretude do cotidiano escolar. 
A própria semântica evasiva desse mote pedagógico funciona como força componente estratégica desse dispositivo educacional-escolar. Aqui, os enunciados ganham materialidade pelo modo como produzem o dispositivo, pois atuam discursivamente, de maneira performativa, gerando efeitos de verdade no jogo educacional cotidiano (FOUCAULT, 1998a).

É nesse sentido que o Enem como prática avaliativa, por acionar um modo de operacionalizar e validar um tipo de conhecimento na própria cena escolar cotidiana, configura também uma prática curricular. Daí a necessidade de considerar essa experiência como relevante vetor de produção de uma política de pensamento, situação esta que demanda uma atenção crítica por parte de todos os envolvidos com questões educacionais.

Ao embaralhar as fronteiras entre o avaliativo e o curricular, o jogo do dispositivo produz algo muito singular: seu efeito examinatório não incide exatamente na busca de padronização de resultados de excelência, tomados como valores em abstrato, nem na efetivação e mensuração do que seria, substancialmente, esse domínio de eixos cognitivos, competências e habilidades.

A força política desse dispositivo advém da peculiaridade de seu mecanismo de normalização, com seu efeito de mapeamento contínuo tanto do espectro das operações intelectivas individuais socialmente úteis, quanto do desempenho cognitivo geral da população.

É no corpo a corpo do cotidiano escolar que se realizam esforços de aproximação frente às inefáveis demandas de aprendizado do pensamento. Exemplo emblemático encontra-se na tendência crescente, por parte das instituições escolares de ensino médio, de tomar as próprias provas aplicadas do Enem como norte de práticas curriculares, de modo a produzir estratégicos ajustes cognitivos, retroalimentando assim a prática do exame.

O foco do processo educacional não seria o alcance de metas cognitivas tomadas como referências absolutas. Em vez de padronização, seria assertivo falarmos de normalização do pensamento, pois o investimento contínuo nesse trabalho examinatório, que se dilui por todo o período letivo, torna-se o próprio corpo da educação.

Assim, a condição estrategicamente vaga dessa espécie de regência normativa pautada no aprender a pensar e combinada ao trabalho cotidiano com as questões da prova atuam conjuntamente na (re)produção de uma forma particular de pensamento - movido pela reflexividade da razão e voltado aos objetivos da recognição e, portanto, do (re)conhecimento.

A contingência do Enem produz a modulação das práticas pedagógicas, implicando-as num esforço de ressonância normativa do pensar. Tal modulação 
normativa "educa" alunos, professores, equipe técnica do Estado, entre outros, implicando-os em seus respectivos fazeres institucionais, viabilizando as políticas de gestão educacional. Eis a normalização do pensar.

Estamos no coração do governo dos homens e, particularmente, tocamos a própria medula dos processos de governamentalização do pensamento no domínio educacional-escolar contemporâneo.

Ao abordar a questão do governo, Foucault (1995) nos alerta para as formas de sofisticação dos mecanismos de poder na sociedade capitalista contemporânea. Para o pensador francês, o exercício do poder

[...] é um conjunto de ações sobre ações possíveis; ele opera sobre o campo de possibilidade onde se inscreve o comportamento dos sujeitos ativos; ele incita, induz, desvia, facilita ou torna mais difícil, amplia ou limita, torna mais ou menos provável; no limite, ele coage ou impede absolutamente, mas é sempre uma maneira de agir sobre um ou vários sujeitos ativos, e o quanto eles agem ou são suscetíveis de agir. Uma ação sobre ações. (p. 243)

$\mathrm{O}$ ato de governar não remeteria a ações de disciplinamento pontual de indivíduos; ao contrário, governar implicaria ações de gestão em relação à totalidade das condutas de determinada população. Governar é "conduzir condutas" e ordenar a probabilidade, diz Foucault (op. cit.). A prática da gestão demanda cálculos de probabilidades de ações possíveis - daí sua eficácia como política de controle. Compreende-se por governamentalidade esse "[...] conjunto constituído pelas instituições, procedimentos, análises e reflexões, cálculos e as táticas que permitem exercer essa forma bastante específica, embora muito complexa, de poder, que tem por alvo principal a população" (FOUCAULT, 2008b, p.143).

Assim, a abordagem de problemas relativos à gestão de populações evoca discussões de ordem biopolítica, ou seja, aquelas que remetem ao uso de mecanismos de previsibilidade, estimativas estatísticas, medições globais que possibilitariam uma intervenção estratégica no âmbito dos fenômenos gerais que afetam o corpo da população (FOUCAULT, 1999a).

Quanto às relações de poder, o deslocamento da ênfase na ação sobre o indivíduo - marca dos mecanismos disciplinares - para uma ação sobre o espectro das condutas de uma população torna-se a estratégia política da governamentalidade. Ocorreria, de acordo com Foucault (1999a), um efeito de regulamentação e não de disciplinarização social, pois se buscaria, prioritariamente, gerir a condição aleatória dos fenômenos globais, tendo em vista a segurança do corpo populacional.

A prevalência da gestão dos fluxos em detrimento da fixidez disciplinar é assim descrita: 
[...] a sociedade não tem uma necessidade indefinida de conformidade. [...] não tem a menor necessidade de obedecer a um sistema disciplinar exaustivo [...]. Tem-se, ao contrário, no horizonte disso, a imagem ou a ideia ou o tema-programa de uma sociedade na qual haveria otimização dos sistemas de diferença em que o terreno ficaria livre para os processos oscilatórios, em que haveria uma tolerância concedida aos indivíduos e as práticas minoritárias, na qual haveria uma ação não sobre os jogadores do jogo, mas sobre as regras do jogo, e, enfim, na qual haveria uma intervenção que não seria do tipo da sujeição interna dos indivíduos, mas uma intervenção de tipo ambiental. (FOUCAULT, 2008a, p. 354355 , grifos nossos)

A metáfora do jogo anuncia nosso terreno movediço: promover a mobilidade dos jogadores sociais e ao mesmo tempo assegurar o lugar de zelo às regras. É na multiplicidade, indeterminação e flexibilização das ações sociais que se encontra a senha tecnológica dos processos de gestão ou governamentalização da vida.

Uma vez produtoras de qualificação do capital humano, as práticas educacionais atuam como tecnologias biopolíticas estratégicas, pois substancializam fortemente esses processos de governamentalização. Foucault (2008a, p. 315) é assertivo em relação a esse aspecto: "formar capital humano, formar portanto essas espécies de competência-máquina que vão produzir renda, ou melhor, que vão ser remuneradas por renda, quer dizer o quê? Quer dizer, é claro, fazer o que se chama de investimentos educacionais".

Portanto, nosso problema remete à crítica a certa economia do pensamento em educação. A peculiar fluidez normativa subjacente ao princípio do aprender a aprender parece adequar-se fortemente à dinâmica de governamentalidade do pensamento, ao menos, por duas razões.

De largada, a inapreensível formulação pedagógica aprender a aprender assegura a modulação necessária do pensar, pois, por meio de uma polissemia estratégica, inaugura um amplo espectro de possibilidades cognitivas dos alunos-jogadores. Estas, entretanto, se limitam às formas exigidas de desempenho, mensuradas a partir de operações cognitivas definidas previamente. Atuando pela força do paradoxo, a eficácia tangível dessa maquinaria de gestão educacional parece residir exatamente no efeito intangível desse eixo normativo-cognitivo que institui o aprendizado do aprender. De modo complementar e simultâneo, a crescente expansão e a relevância avaliativa do Enem, em termos de sua força política como passaporte para o ensino superior, expressam a prevalência das regras do jogo do pensar. Como efeito geral, mantém-se preservada a gestão da vida ancorada numa modalidade de pensamento pautada pela recognição e atestada como performance frente às situações-problema estratégicas.

Por encontrar-se em xeque tanto a produção de efeitos de subjetivação quanto de formas de vida, ambos talhados nessa experiência do pensar como recognição performativa, urge-nos indagar: o que pode o pensamento?

Lancemo-nos, pois, à companhia de Nietzsche. 


\section{Conhecimento e pensamento}

Do legado do filósofo alemão, interessa-nos resgatar pontualmente algumas problematizações sobre o conhecimento. Afirmamos que sua crítica à cultura ocidental moderna mantém-se contemporânea, na medida em que se constitui como importante instrumental analítico de exploração das relações entre linguagem e poder.

Numa orientação nietzschiana, Foucault (1999b) sustenta que o conhecimento não é da ordem da naturalidade nem produto de harmonização entre os homens, mas está vinculado à vontade de verdade e configura-se como efeito de combate entre valores. De acordo com essa premissa, o conhecimento é uma invenção do homem. Por constituir-se como força resultante de determinadas estratégias, possui um caráter genealogicamente parcial, perspectivo. "Pode-se falar do caráter perspectivo do conhecimento porque há batalha e porque o conhecimento é o efeito dessa batalha" (FOUCAULT, 1999b, p. 25).

O conhecimento não seria expressão asséptica de uma adequação linguística entre sujeitos, palavras e coisas, mas implicaria conflito de valores e produção de verdades, ou melhor, de efeitos de verdade. Tal combate confere à verdade um estatuto contingencial, fruto do perspectivismo - a verdade não seria mais do que uma expressão pontual do posicionamento dessas disputas históricas entre valores.

Em suas análises, Nietzsche (2001, p. 138) afirma que "o conhecimento e a busca do verdadeiro finalmente se incluíram, como necessidade, entre as necessidades". O impulso à verdade seria, sobretudo, um mecanismo necessário ao homem e estaria ligado ao poder de conservação da vida.

A articulação entre vontade de verdade, conhecimento e valores incita-nos a uma atitude genealógica: dada a condição contingencial do conhecimento e seus efeitos de verdade, faz-se necessário tomá-los invariavelmente como alvos passíveis de constantes problematizações.

Encontramo-nos no âmago de uma discussão ético-política em relação ao pensar. Ao colocar em evidência o caráter político do conhecimento e do ato de conhecer, Nietzsche nos oferece as pistas para uma crítica aos processos linguísticos que remetem ao ato de pensar. De forma lapidar, o filósofo nos provoca com sua ironia mordaz:

Todo conceito nasce por igualação do não igual. Assim como é certo que nunca uma folha é inteiramente igual a uma outra, é certo que o conceito de folha é formado pelo arbitrário abandono dessas diferenças individuais, por um esquecer-se do que é distintivo, 
e desperta então a representação, como se na natureza além das folhas houvesse algo, que fosse "folha", eventualmente uma folha primordial, segundo a qual todas as folhas fossem tecidas, desenhadas, recortadas, coloridas, frisadas, pintadas, mas por mãos inábeis, de tal modo que nenhum exemplar tivesse saído correto e fidedigno como cópia fiel da forma primordial. [...] mais uma vez: a folha é a causa das folhas. (NIETZSCHE, 2008, p. 56)

A citação sugere que a linguagem do clássico processo do conhecer, lastro da Modernidade, tem se efetivado pelo jogo representacional. Assim, o ato de conhecer tem se constituído como operacionalização de um pensamento reflexivo, cujo objetivo seria alcançar a aderência entre os supostos sujeito e objeto do conhecimento.

A circularidade presumida nessa prática de pensamento seria a própria manifestação de uma vontade de verdade, ou, mais precisamente, de certa economia de relações de poder, na medida em que tenderia a naturalizar e reafirmar valores considerados legítimos para dado tempo histórico.

Torna-se crucial destacarmos a atualidade desse problema formulado por Nietzsche em relação ao conhecimento. O exercício de um pensamento circular produziria um mero re-conhecimento das senhas históricas, simples trabalho de decodificação e recodificação das cifras vigentes do mundo.

A questão do reconhecimento como um dos efeitos impotentes da cultura moderna é um problema central para o filósofo alemão. Em um de seus aforismos, ele sintetiza:

Essa explicação eu encontrei na rua; ouvi alguém do povo dizer: "Ele me reconheceu" então me perguntei: o que entende mesmo o povo por "conhecimento"? O que quer ele, quando quer "conhecimento"? Não mais do que isso: algo estranho deve ser remetido a algo conhecido. [...] nossa necessidade de conhecer não é justamente essa necessidade do conhecido, a vontade em meio a tudo o que é estranho, inabitual, duvidoso, descobrir algo que não mais nos inquiete? Não seria o instinto do medo que nos faz conhecer? E o júbilo dos que conhecem não seria precisamente o júbilo do sentimento de segurança reconquistado? (NIETZSCHE, 2001, p. 250-251)

O processo do conhecimento como operação cognitiva de reconhecimento não se constitui objeto de uma questão meramente epistemológica. Na trilha nietzschiana, afirmamos que a valoração de uma operação cognitiva, baseada na reflexividade do pensamento e no consequente efeito de re-conhecimento e legitimação do tal mundo re-conhecido, atende às necessidades humanas de conservação das condições da vida, ou seja, de segurança frente à ordem civilizatória. É nesse sentido que a prevalência de uma linguagem de pensamento, fundada no jogo do reconhecimento ou recognição do mundo, por acionar um conjunto de valores vitoriosos que a legitima, não se situa à margem de implicações éticas e políticas. 
A atualidade dessa crítica reverbera intensamente em nosso campo educacional, pois coloca sub judice os jogos de pensamento e de pensar que, para além das práticas pedagógicas, têm consubstancializado certo horizonte de sociedade.

Torna-se, pois, inescapável a questão: do ponto de vista da formação educacional de um Estado-nação, quais os efeitos políticos - em termos de modos de subjetivação ou de produção de formas sociais de vida - de uma educação do pensamento ancorada em estratégias performativas e voltada ao trabalho de reconhecimento ou recognição linguística?

\section{Arena ético-política do pensamento e educação}

Nos rastros de tais inquietações, Foucault (2005) insiste na necessidade de problematização do modo como nos relacionamos com a verdade em nosso tempo presente, a partir da validação de certa política de conhecimento e de pensamento. Atiça-nos:

[...] qualquer verdadeiro problema deve ter uma solução, pois pertencemos à escola de um mestre que só pergunta a partir das respostas inteiramente escritas em seu caderno, o mundo é nossa sala de aula. Ínfimas crenças... [...]. É preciso nos libertarmos disso. (FOUCAULT, 2005, p. 242-243)

Não podemos nos furtar às ironias do autor, quando nos remete, por simetria, ao universo da escola. "O mundo é nossa sala de aula" é expressão de um modo de relação dos homens com as coisas, consigo próprios e consigo mesmos, o qual supõe o conhecimento como experiência de apropriação e domínio desse mundo. A eficácia desse "modelo escolar" residiria no exercício de suas trucagens nos jogos de perguntas e respostas, bem como nos efeitos de repetição, previsibilidade e aplicabilidade daí decorrentes.

A provocação delata a prevalência cultural de um modo pedagógico de relacionamento com a vida, caracterizado por um pensar competente, hábil na manipulação de variáveis previstas pelas múltiplas linguagens do conhecer - das ciências às artes.

Num cenário em que o próprio pensamento se encontra refém de seu tempo histórico, o autor propõe uma atitude genealógica que buscaria estabelecer, de forma agonística, uma contínua e radical interrogação do presente. A questão do pensamento ocupa um lugar estratégico nessa analítica, uma vez que, por implicar os modos de produção da vida, remete a uma problematização ética e convoca a uma necessária esteticização das formas de existência.

A radicalidade da experiência do pensar residiria na abertura ao imponderável do próprio pensamento. Caberia a este promover a ultrapassagem dos limites do 
pensável, suscitando seu próprio impensável, corrompendo as malhas linguísticas tecidas nas relações de poder. Num salto diferencial, o pensamento poderia forjar o radical acesso ao seu próprio fora, à sua própria exterioridade - gesto incansável de estranhamento e desnaturalização da verdade, essa matéria de presentificação do mundo e de nós mesmos (FOUCAULT, 2001, 2005).

Pensar - diferentemente de (re)conhecer - seria instaurar uma diferença incapturável pelo pensável, ou seja, "liberar o pensamento daquilo que ele pensa silenciosamente, e permitir-lhe pensar diferentemente" (idem, 1998b, p. 14). É nesse sentido que o pensamento "é, em si mesmo, uma ação - um ato perigoso" (idem, 1999c, p. 453).

Essas inflexões nietzschianas e foucaultianas não são extemporâneas diante dos atuais dilemas da educação no Brasil. Por meio delas, buscamos colocar em cena algumas questões que ultrapassam demandas técnicas de gestão curricular ou avaliação sistêmica. Trata-se de atentar para os efeitos de políticas de pensamento que têm se naturalizado no campo educacional, tomando o Enem uma experiência paradigmática.

O último Relatório de Desenvolvimento Humano - $20^{\circ} \mathrm{RDH}-$, com seus novos padrões mais qualitativos de mensuração, indicou que o comprometimento do fator educação emerge como o principal aspecto - além de saúde e renda - que tem afetado a vida da população em estado de privação - parcela que congrega $8,5 \%$ dos brasileiros. Os problemas de gestão educacional enfrentados pelo Brasil se expressam no ranking mundial: encontramo-nos na 73ª posição entre 169 países (PNUD, 2010).

Dada a força discursiva desse diagnóstico, o Brasil tende a validar os regimes de avaliação de desempenho (de ordem individual e sistêmica) que possam viabilizar a melhoria de sua posição política e econômica em termos mundiais.

Nesse cenário árido, marcado por fortes demandas de qualidade formativa, as discussões sobre o pensamento como mera estratégia de recognição tendem a ser pulverizadas como um problema menor, diante do horizonte catastrófico e emergencial da educação nacional. Tal situação só corrobora o atual jogo dos regimes de verdade, com suas estratégias de valoração daquilo que se postula como um pensar competente.

A despeito das vantagens sociais que um aprendizado de recognição por via performática possa oferecer, bem como dos impactos políticos que o Enem vem conquistando em termos de acesso público ao ensino superior, mantemo-nos refratários à ideia de que o pensar deva ser um mero jogo cognitivo voltado ao reconhecer. Isso tende à restrição do conhecer a simples artifício de representação

Dado nosso percurso, indagamos: esse suposto aprender a pensar não se restringe a aprender a pensar o pensável? Essas estratégias não comprometeriam as 
possibilidades de pensar o impensável, educando tão somente para a reverberação de um pensar cativo? Quais as implicações desse modo de tomar o pensamento quando, em termos de políticas públicas, essas práticas conformam o futuro do pensamento, no sentido de produzirem o aluno do ensino superior? Em que medida podemos, em nome das metas de gestão cognitiva, reduzir a relevância das implicações entre as políticas de pensamento e a configuração futura de uma sociedade?

Perpassados pela lança nietzschiana, apostemos numa informe potência do pensar como uma experiência que não se confunde com a forma-conhecer. Ao mesmo tempo, atados à fatalidade dessa arena que insiste em dragar as forças do pensamento, não negligenciemos a potência trágica dos fazeres possíveis que ali se move, convulsivamente.

Na condição de pesquisadores, educadores e gestores, faz-se necessário afirmar um horizonte estético e ético-político em relação à experiência do pensar, de modo que se possa manter aberto o campo do debate, rechaçando os consensos fáceis que tendem a silenciar as questões cruciais.

Num tempo em que os processos de governamentalização educacional e da vida confundem-se com estratégias virtuosas para a condição humana, a permanência no estado de espreita assegura o contínuo tensionamento do debate, de modo que se possa, lenta e incisivamente, deslocar o lugar do pensamento em educação para além do jogo performático do reconhecimento. A presente escritura inscreve-se nessa arena ético-política.

\section{Referências}

AZANHA, J.M.P. A formação do professor e outros escritos. São Paulo: Senac, 2006.

BRASIL. Ministério da Educação. Instituto Nacional de Estudos e Pesquisas Educacionais Anísio Teixeira (INEP). Enem: documento básico. Brasília, DF: MEC; Inep, 2002. Disponível em: <http://historico.enem.inep.gov.br/index.php?option=com_ content\&task=view\&id=29\&Itemid=60>. Acesso em: 27 nov. 2010.

BRASIL. Ministério da Educação. Instituto Nacional de Estudos e Pesquisas Educacionais Anísio Teixeira (INEP). Matriz de referência para o Enem 2009. Brasília, DF: MEC; Inep, 2009a. Disponível em: <http://portal.mec.gov.br/index.php?option=com_content \&view=article\&id=13318\&Itemid=310> Acesso em: 27 nov. 2010.

BRASIL. Ministério da Educação. Instituto Nacional de Estudos e Pesquisas Educacionais Anísio Teixeira (INEP). Matriz de referência do Enem 2009. Aprovação pelo Comitê de Governança do Novo Enem representados pelo MEC, Inep e Andifes. 
Brasília, DF: MEC; Inep; Andifes, 2009b. Disponível em: <http://portal.mec.gov.br/ dmdocuments/matriz_referencia_novoenem.pdf >. Acesso em: 27 nov. 2010.

BRASIL. Ministério da Educação. Instituto Nacional de Estudos e Pesquisas Educacionais Anísio Teixeira (INEP). Portaria n. 807, de 18 de junho de 2010. Institui o Exame Nacional do Ensino Médio. Brasília, DF: MEC; Inep, 2010a. Disponível em: <http:// www.enem.inep.gov.br/pdf/portaria807_180610.pdf>. Acesso em: 27 nov. 2010.

BRASIL. Ministério da Educação. Instituto Nacional de Estudos e Pesquisas Educacionais Anísio Teixeira (INEP). Edital n. 01, de 18 de junho de 2010. Torna pública a realização do Exame Nacional do Ensino Médio no exercício de 2010 - Enem 2010. Brasília, DF: MEC; Inep, 2010b. Disponível em: <http://www.enem.inep.gov.br/pdf/ edital_enem2010_atualizado_081010.pdf>. Acesso em: 27 nov. 2010.

DELORS, J. Educação: um tesouro a descobrir. São Paulo: Cortez; Brasília, DF: MEC; Unesco, 2002.

FOUCAULT, M. O sujeito e o poder. In: RABINOW, P.; DREYFUS, H. Michel Foucault: uma trajetória filosófica para além do estruturalismo e da hermenêutica. Rio de Janeiro: Forense Universitária, 1995.

FOUCAULT, M. Microfísica do poder. Rio de Janeiro: Graal, 1998a.

FOUCAULT, M. História da sexualidade 2: o uso dos prazeres. Rio de Janeiro: Graal, 1998b.

FOUCAULT, M. Em defesa da sociedade: curso no Collège de France (1975-1976). São Paulo: Martins Fontes, 1999a.

FOUCAULT, M. A verdade e as formas jurídicas. Rio de Janeiro: Nau, 1999b.

FOUCAULT, M. As palavras e as coisas: uma arqueologia das ciências humanas. São Paulo: Martins Fontes, 1999c.

FOUCAULT, M. O pensamento do exterior. In: FOUCAULT, M. Ditos E Escritos III estética: literatura e pintura, música e cinema. Rio de Janeiro: Forense Universitária, 2001.

FOUCAULT, M. Theatrum philosophicum. In: FOUCAULT, M. Ditos E Escritos II: arqueologia das ciências e história dos sistemas de pensamento. Rio de Janeiro: Forense Universitária, 2005.

FOUCAULT, M. Nascimento da biopolítica: curso dado no Collège de France (19781979). São Paulo: Martins Fontes, 2008a.

FOUCAULT, M. Segurança, território, população: curso dado no Collège de France (1977-1978). São Paulo: Martins Fontes, 2008b. 
GALEANO, E. O livro dos abraços. Porto Alegre: L\&PM, 2009.

NIETZSCHE, F. Genealogia da moral: uma polêmica. São Paulo: Cia das Letras, 1998.

NIETZSCHE, F. A gaia ciência. São Paulo: Companhia das Letras, 2001.

NIETZSCHE, F. Sobre verdade e mentira. São Paulo: Hedra, 2008.

PROGRAMA DAS NAÇÕES UNIDAS PARA O DESENVOLVIMENTO (PNUD). A verdadeira riqueza das nações: caminhos para o desenvolvimento humano; relatório de Desenvolvimento Humano 2010. Brasília, DF: PNUD, 2010. Disponível em: <http:// hdr.undp.org/en/reports/global/hdr2010/chapters/pt/>. Acesso em: 27 nov. 2010.

SILVA, T.T. Documentos de identidade: uma introdução às teorias do currículo. Belo Horizonte: Autêntica, 2001.

Recebido em 4 de dezembro de 2010.

Aprovado em 25 de setembro de 2013. 